DOI: http://doi.org/10.21698/simi.2018.fp13

\title{
PHYSICAL MODELING OF FLOW OVER AN OGEE SPILLWAY AND INVESTIGATION OF SCALE EFFECTS BY USING FROUDE SIMILARITY
}

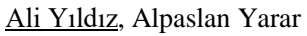

Selcuk University Civil Engineering Department, 369 Akademi Mah. Yeni Istanbul Cad., 42130, Selcuklu-Konya, aliyildiz@sekcuk.edu.tr, ayarar@selcuk.edu.tr, Turkey

\begin{abstract}
Ogee spillways are used to control the discharges and water levels in reservoir. In some cases, steps and baffle blocks are placed at the stilling basin to change flow regime supercritical to subcritical and improve energy dissipation. Physical models are built in the laboratories to represent its real-world prototype; however some scale effects may arise between models. Two open channel setups, called as model and prototype, are used in this study. The experiments of the study are performed on these channels using identical Froude Numbers and geometric scaling ratio of 4:1. The flow depths at four different points are measured from model and prototype for 28 total head. The results showed that there is $92 \%$ consistency between model and prototype, whereas this consistency was not observed at turbulence existing regions due to scale effects.
\end{abstract}

Keywords: dimensional analysis, Froude similarity, hydraulic simulate, ogee spillway

\section{Introduction}

Dams are large obstacle structures and constructed from different materials in different types for preventing, directing and delaying flow of water to create a lake or reservoir. Water is an important natural resource of human, animals and plants life therefore studies for water usage is begin with the existence of mankind. Dams are built for many purposes such as drinking water, irrigation, energy production and transportation. A dam's body basically composed of reservoir, spillway, bottom sluice, water intake structure and energy generation facilities.

Spillways transfer the excessive water coming to dam reservoir to downstream side in safe and controller manner. Spillways have an important place in dams in terms of operation and stabilization of dam. $22 \%$ of the dam damages are caused by insufficient spillway capacity and their faulty operation (ICOLD 1995).

Physical models of dams are built, to project dams in the best way. A physical model represent the actual prototype to be built in real life and model is used as a tool to find the most technical and economical solution (Novak 1984). The reliability of a physical model depends on correct construction. If the model is built incorrectly, error in the data obtained from the model will increase (Yalin 1989).

There are some numerical ratios and scales that must be taken into account when constructing the physical model. Scale ratio between physical model and prototype is important. As the scale ratio is reduced, error caused by scale effect is increased and the results obtained from model and prototype is getting away. Scale effect arise 


\section{INTERNATIONAL SYMPOSIUM "THE ENVIRONMENT AND THE INDUSTRY", SIMI 2018, PROCEEDINGS BOOK}

due to coefficient of the associated force ratio between the model and prototype is not kept constant (Huger 1993). Incorrect modelling of flow conditions, turbulence intensity and fluid properties also causes scale effects.

In this study, physical modelling of hydraulic structures has been studied. In this study, 2 experimental setups which are called model and prototype are used. The scale ratio between model and prototype is 4 . Froude similarity is applied to results of model to predict experimental result of prototype.

\section{Materials and Methods}

\section{Ogee spillway design and experimental study}

The ogee spillway is a control weir having an ogee (S-shaped) overflow profile. It is one of the most used spillway type in hydraulic structures because of its ability to pass flood flow out of reservoir safely. Ogee spillway idea is first recommended by (Muller 1908). A typical ogee spillway can be seen in Figure 1.

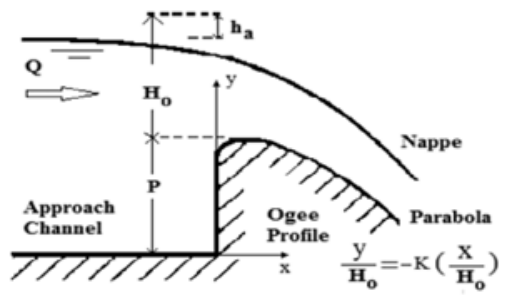

Figure 1. Flow over and ogee spillway.

The general equation for discharge over an ogee crested spillway is given as (USBR 1987):

$$
\mathrm{Q}=\mathrm{C}_{0} * \mathrm{~L}^{*} \mathrm{H}_{0}{ }^{1.5}
$$

where $\mathrm{Q}=$ total discharge, $\mathrm{L}=$ lateral crest width, $\mathrm{C}_{0}=$ crest coefficient and $\mathrm{H}_{0}=$ total head upstream from crest.

The small open channel construction used as model is $400 \mathrm{~cm}$ long, $7.5 \mathrm{~cm}$ wide and $20 \mathrm{~cm}$ deep. The model experimental setup is a simple flume and made of smooth transparent plastic. The slope of flume is set zero. Dimensions for ogee spillway model used in model are $(\mathrm{P})_{\text {model }}=7 \mathrm{~cm}$ (crest height), $\mathrm{L}_{\text {model }}=7,5 \mathrm{~cm}$ (crest length) and $\mathrm{C}_{0}=2.17$ (discharge coefficient). The general view of model setup and ogee spillway can be seen Figure 2. The ogee spillway used in model is fabricated from stainless steel. The water flow in the model setup is provided by a pump which gives the Qmax=4 l/s.

The large open channel construction used as prototype is $650 \mathrm{~cm}$ long, $30 \mathrm{~cm}$ wide and $50 \mathrm{~cm}$ deep. The slope of the channel is zero same as model setup. The prototype open channel is made of tempered glass. The spillway model used in prototype is made from plexiglas. Dimensions for ogee spillway used in prototype are $(P)_{\text {prototype }}=28 \mathrm{~cm}$, and $\mathrm{L}_{\text {prototype }}=30 \mathrm{~cm}$ and $\mathrm{C}_{0}=2.17$. Crest height and crest length of spillway used in prototype is 4 times larger than the spillway used in model because of scale ratio (Figure 2). 


\section{INTERNATIONAL SYMPOSIUM "THE ENVIRONMENT AND THE INDUSTRY", SIMI 2018, PROCEEDINGS BOOK}
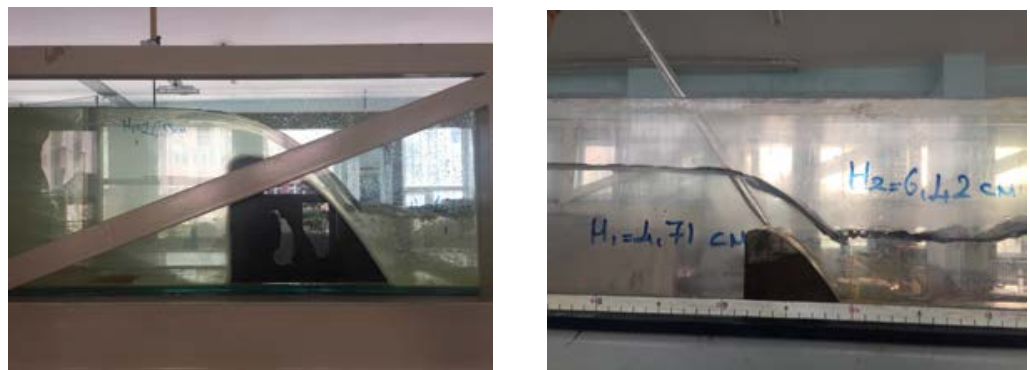

Figure 2. Spillway models used in model and prototype

Specifications of the ogee spillway which is used in the tests that downstream portion profile of ogee is determined as constants given below for both model and prototype (USACE 1985);

$$
\mathrm{Y} / \mathrm{H}_{\mathrm{d}}=-\mathrm{K}^{*}\left(\mathrm{X} / \mathrm{H}_{\mathrm{d}}\right)^{\mathrm{n}}
$$

where $\left(\mathrm{H}_{\mathrm{d}}\right)_{\text {model }}=3.6 \mathrm{~cm}$ and $\left(\mathrm{H}_{\mathrm{d}}\right)_{\text {prototype }}=14.4 \mathrm{~cm}$. $\mathrm{K}$ is chosen 0.5 and $\mathrm{n}$ is chosen 1.85 for both model.

\section{Hydraulic similitude}

A physical model represents its real-world prototype. Physical models are commonly used design stage of prototype to optimize a structure and ensure safe operation after constriction. A physical model is valid only if these three criteria is satisfied; geometric similarity, kinematic similarity and dynamic similarity. Geometric similarity is a geometric ratio between prototype and model. In this study geometric ratio between models $\mathrm{Lr}=4$ is taken.

Kinematic similarity is that similarity of motion between model and prototype particles. In this study velocity ration $\mathrm{V}_{\mathrm{r}}=2$ and discharge ratio $\mathrm{Q}_{\mathrm{r}}=32$ is taken.

Dynamic similarity means that all force ratio in the model and prototype are identical. Froude similarity is used in experiments. It means that model and prototype have identical Froude numbers. $(\mathrm{Fr})_{\text {model }}=(\mathrm{Fr})_{\text {prototype }}$

\section{Dimensional analysis}

Before building a physical model in the laboratory dimensional analysis is applied to determine relationships between model and prototype. Dimensional analysis gives dimensionless quantities appear in both models. Dimensional analysis shows that Froude number is seen in both model so that Froude similarity is used (Buckingham 1914).

\section{Results and Discussion}

Results obtained from physical model and prototype were evaluated and compared according to hydraulic similarity rules in terms of flow depths and water surface profiles. The aim of the comparing flow depths is to determine how the flow profiles of models and prototype are consistent with each other and hydraulic similarity rules.

Firstly water surface profile of model and prototype is compared. The purpose of the comparing the flow profiles is to determine how the flow profiles of the model and 


\section{INTERNATIONAL SYMPOSIUM "THE ENVIRONMENT AND THE INDUSTRY", SIMI 2018, PROCEEDINGS BOOK}

prototype are consistent with each other and whether they are consistent with the hydraulic homogeneity rules. When comparing the general flow profiles, it was also investigated by observing whether there is a difference in the profiles due to the scale effect. When general flow profiles are investigated, it is seen that the model and the prototype show high consistency (Figures 3, 4).

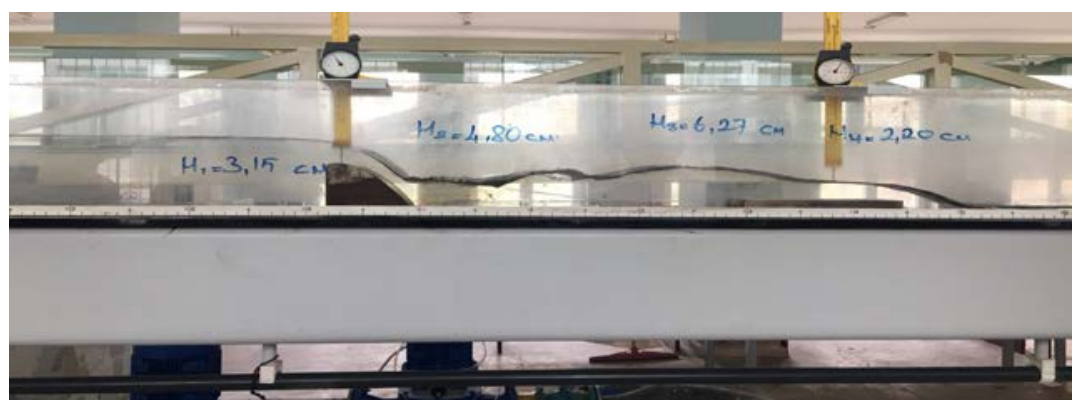

Figure 3. Water surface profiles at model

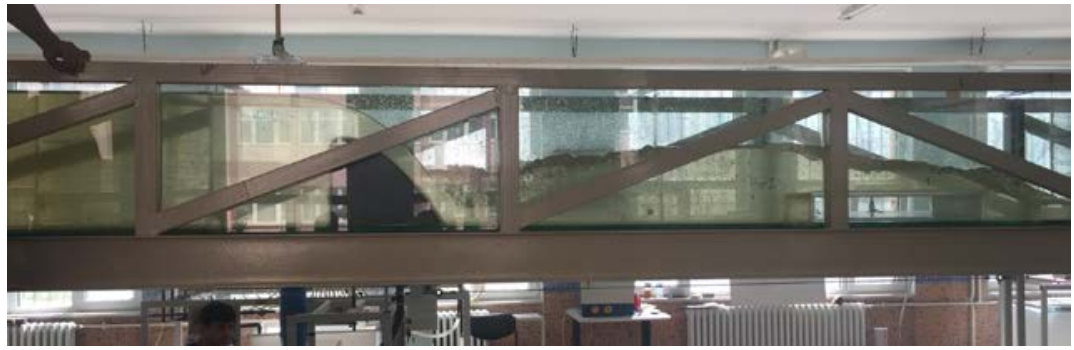

Figure 4. Water surface profiles at prototype

Flow depths are measured at four different points (shown in Figure 5) and flow rates are measured for both model and prototype. The ratio of flow rates between model and prototype must be same with geometric ratio $\mathrm{Lr}_{\mathrm{r}}=4$. Therefore, 4 times larger ogee spillway model is used in prototype.

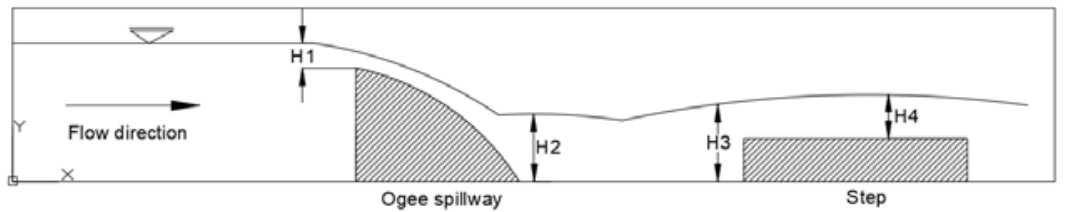

Figure 5. General view of models and position of measurement points

The discharge ratio between model and prototype should be $\mathrm{Q}_{\mathrm{r}}=32$. The results obtained from model and prototype can be seen in Table 1 and Table 2 respectively. 
Table 1. Flow depths get from model at 4 different points and discharge values

\begin{tabular}{ccccc}
\hline \multicolumn{5}{c}{ Flow depths and Discharge Measurement for Model Setup } \\
\hline $\mathrm{H}_{1}(\mathrm{~m})$ & $\mathrm{H}_{2}(\mathrm{~m})$ & $\mathrm{H}_{3}(\mathrm{~m})$ & $\mathrm{H}_{4}(\mathrm{~m})$ & $\mathrm{Q}_{\text {model }}(\mathrm{l} / \mathrm{s})$ \\
\hline 0.0165 & 0.0341 & 0.0450 & 0.0110 & 0.33 \\
0.0225 & 0.0390 & 0.0507 & 0.0155 & 0.56 \\
0.0260 & 0.0424 & 0.0557 & 0.0178 & 0.71 \\
0.0290 & 0.0465 & 0.0592 & 0.0203 & 0.86 \\
0.0307 & 0.0470 & 0.0610 & 0.0215 & 0.94 \\
0.0341 & 0.0503 & 0.0652 & 0.0251 & 1.11 \\
0.0365 & 0.0533 & 0.0675 & 0.0278 & 1.22 \\
0.0384 & 0.0555 & 0.0703 & 0.0295 & 1.40 \\
\hline
\end{tabular}

Table 2. Flow depths get from prototype at 4 different points and discharge values

\begin{tabular}{ccccc}
\hline \multicolumn{5}{c}{ Flow depths and Discharge Measurement for Prototype Setup } \\
\hline $\mathrm{H}_{1}(\mathrm{~m})$ & $\mathrm{H}_{2}(\mathrm{~m})$ & $\mathrm{H}_{3}(\mathrm{~m})$ & $\mathrm{H}_{4}(\mathrm{~m})$ & Qprotype $(\mathrm{l} / \mathrm{s})$ \\
\hline 0.067 & 0.132 & 0.176 & 0.046 & 10.56 \\
0.091 & 0.152 & 0.211 & 0.062 & 17.88 \\
0.104 & 0.171 & 0.225 & 0.071 & 22.84 \\
0.116 & 0.173 & 0.240 & 0.087 & 27.43 \\
0.123 & 0.183 & 0.247 & 0.091 & 30.10 \\
0.136 & 0.200 & 0.269 & 0.101 & 35.63 \\
0.145 & 0.210 & 0.279 & 0.118 & 40.31 \\
0.150 & 0.218 & 0.282 & 0.121 & 43.51 \\
\hline
\end{tabular}

When flow depths, discharges values obtained from model and prototype are compared, there is a high consistency with the values of $\mathrm{L}_{\mathrm{r}}=4$ (geometric ratio) and $\mathrm{Q}_{\mathrm{r}}=32$ (discharge ratio) used in the Froude Smilarity law (Table 3).

Table 3. When Discharge Ratio $\left(\mathrm{Q}_{\mathrm{r}}=32\right)$ is provided, controlling the ratio of flow depths $\left(\mathrm{Lr}_{\mathrm{r}}=4\right)$

\begin{tabular}{ccccc}
\hline$\left(\mathrm{H}_{1}\right)_{\mathrm{p}} /\left(\mathrm{H}_{1}\right)_{\mathrm{m}}$ & $\left(\mathrm{H}_{2}\right)_{\mathrm{p}} /\left(\mathrm{H}_{2}\right)_{\mathrm{m}}$ & $\left(\mathrm{H}_{3}\right)_{\mathrm{p}} /\left(\mathrm{H}_{3}\right)_{\mathrm{m}}$ & $\left(\mathrm{H}_{4}\right)_{\mathrm{p}} /\left(\mathrm{H}_{4}\right)_{\mathrm{m}}$ & $\mathrm{Q}_{\text {prototype }} / \mathrm{Q}_{\text {model }}$ \\
\hline 4.06 & 3.87 & 3.91 & 4.18 & 32.17 \\
4.02 & 3.90 & 4.16 & 4.00 & 31.93 \\
4.01 & 4.03 & 4.04 & 3.99 & 31.99 \\
4.01 & 3.27 & 3.56 & 3.05 & 32.01 \\
3.99 & 3.89 & 4.05 & 4.23 & 31.97 \\
3.99 & 3.98 & 4.13 & 4.02 & 32.02 \\
3.97 & 3.94 & 4.13 & 4.24 & 32.93 \\
3.91 & 3.93 & 4.01 & 4.10 & 30.98 \\
$\mathrm{~L}_{\mathrm{r}}=4$ & $\mathrm{~L}_{\mathrm{r}}=4$ & $\mathrm{~L}_{\mathrm{r}}=4$ & $\mathrm{~L}_{\mathrm{r}}=4$ & $\mathrm{Q}_{\mathrm{r}}=32$ \\
\hline
\end{tabular}

In order for Hydraulic Similarty rules to be valid, Froude numbers should be same in both system. Flow depths obtained from model and prototype at measure point-3 are divided to Total Head $(\mathrm{He}=\mathrm{H} 1)$ to obtain dimensionless reletive flow depth. The relative flow depths of two system and froude numbers at this point is shown in Figure 6. Model and Prototype show good consistency with each other in terms of Hydraulic Similarti rules. 


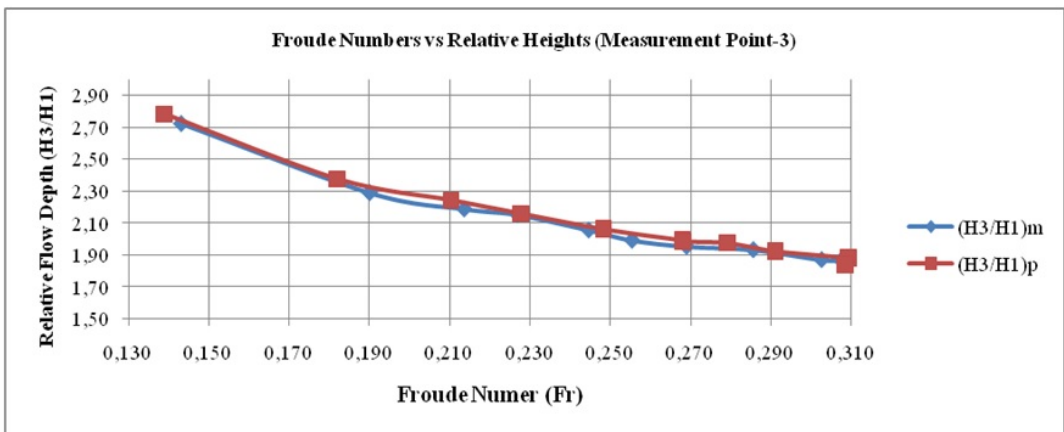

Figure 6. Comparison of Froude Numbers

\section{Conclusions}

Model and prototype show 92\% consistency with each other in terms of flow depths and flow rate. However this consistency was not observed at turbulence existing regions due to scale effects. In this study, hydraulic calculation of an uncontrolled ogee spillway is estimated by a physical model and prototype which are constructed in laboratory. Froude similarity model gives satisfactory results in cases where flow continuous in one direction and without turbulence. When turbulence is high, there are difference between the results of model and prototype. Turbulences have a significant effect on the forces, and these ratio of these forces don't appear to be appropriate for hydraulic similarity rules. These force differences can lead to observe some events that we cannot observe in the model.

\section{References}

Buckingham, E 1914, 'On physical similar systems - Illustrations of the use of dimensional equations', Physical Review, vol. 4, pp. 345-376.

Hughes, SA 1993, 'Advanced series on ocean engineering', Physical Models and Laboratory Techniques in Coastal Engineering, Londra, vol. 7, pp. 27-33.

International Commission of Large Dams 1995, Dam Failures and Statistical Analysis, ICOLD bulletin 99, Paris, pp.75-80.

Muler, R 1908, 'Development of Practical Type of Concrete Spillway Dam', Engineering Rec., vol.58, pp. 461.

Novak, P 1984, 'Scaling factor and scale effects in modeling hydraulic structures', Scale Effects In Modelling Hydraulic Structures, Esslingen, pp.1-5.

U.S. Army Corp of Engineers 1985, General Spillway Investigation, USACE Technical Report Hl-85-1, Washington DC, pp.5-10.

U.S. Department of the Interior Bureau of Reclamation 1987, Design of Small Dams, USBR A Water Resources Technical Publication, Washington DC, pp. 365-375.

Yalın, MS 1989, 'Fundamentals of Hydraulic Physical Modelling', Recent Advances in Hydraulic Physical Modelling, vol. 165, pp.1-6. 